\title{
Peter Sloterdijk: pensar al hombre en una época posthumanista*
}

\section{Peter Sloterdijk: Conceiving the Human Man in a Post-Humanist Era}

\section{Carlos Andrés Méndez Sandoval}

Referencia para citar este artículo: MÉNDEZ SANDOVAL, C. A. (2013). "Peter Sloterdijk: pensar al hombre en una época posthumanista". En: Revista Guillermo de Ockham 11(2). pp. 173-185.

\section{Resumen}

El objetivo del presente documento es hacer un balance crítico de las principales tesis del filósofo alemán Peter Sloterdijk contenidas en dos textos fundamentales, a saber, Reglas para el parque humano y La Domesticatión de l'Etre. El objetivo es reconstruir la crítica sloterdijkeana al humanismo y perfilar los posibles horizontes de reflexión filosófica en torno del acontecimiento de lo humano en una época caracterizada por el acontecimiento del posthumanismo.

Palabras clave: humanismo, posthumanismo, ontoantropología, monstruoso, hombre operable, alotecnología, homeotecnología.

\section{Abstract}

This paper aims to critically analyze the main thesis presented in two fundamental texts of the German philosopher Peter Sloterdijk: Rules for the
Human Zoo and The Domestication de l'Etre. The objective is to reconstruct the Sloterdijk's critical approach on humanism and to define the possible goals of philosophical reflection about the human events in a time characterized by Posthumanism.

Keywords: humanism, Posthumanism, ontoanthropology, huge, The Operable Man, alotechnology, homeotechnology.

\section{Sloterdijk y su crítica al humanismo}

Normas para el parque humano fue, en primera instancia, un documento presentado por Peter Sloterdijk en 1997 durante un ciclo de conferencias sobre la actualidad del humanismo. Dos años después, el filósofo alemán vuelve a presentar su ponencia en unas jornadas de reflexión filosófica dedicadas a Heidegger y Lévinas. Este texto es conocido por el escándalo que suscitaron algunas de las tesis centrales contenidas en él, sobre

- Fecha de recepción del artículo: 05-04-2013 • Fecha de aceptación: 14-06-2013

CARLOS ANDRÉS MÉNDEZ SANDOVAL. Filósofo, Pontificia Universidad Javeriana, Bogotá. Magíster en Filosofía por la Universidad del Valle. Profesor tiempo completo del Centro Interdisciplinario de Estudios Humanísticos (CIDEH) de la Universidad de San Buenaventura, Cali. Correo electrónico: carlosam@usbcali.edu.co.

* Artículo de reflexión del proyecto de investigación “Guerra, poder, gubernamentalidad” adelantado por el grupo de investigación Educación y cultura de la Universidad de San Buenaventura Cali integrado por los docentes Alexánder Muriel Restrepo, Édgar Alonso Vanegas y Carlos Andrés Méndez. Fecha de inicio: mayo de 2012. Fecha de finalización: octubre de 2013. 
todo aquellas que no dudan en dar por liquidada cualquier herencia humanista, además de aquellas alrededor de las biotecnologías y los potenciales efectos positivos que podrían traer para el género humano. Para empezar, vale la pena hacer un recorrido que dé cuenta de algunas tesis centrales planteadas en este polémico ensayo.

En un primer momento, Peter Sloterdijk define el humanismo como una "telecomunicación fundadora de amistades que se realiza en el medio del lenguaje escrito" (Sloterdijk, 2000, p. 19). Lo que se ha definido como humanitas desde la época de Cicerón es el efecto de la transmisión, la interpretación y la asimilación del mensaje filosófico de los griegos. Después de esta recepción latina, las cartas filosóficas de pensadores como Platón y Aristóteles, entre otros, han atravesado el tiempo y el espacio siempre a la espera de nuevos receptores.

En este sentido, lo que se halla en la base comunicativa del humanismo en general es una cierta idea de predestinación a la comunión de un grupo de personas que se reúnen alrededor de un canon de lectura particular y, por obvias razones, de unos ciertos autores denominados clásicos. Por esta razón, afirma Sloterdijk que el humanismo es uno de los resultados de la alfabetización:

En el núcleo del humanismo así entendido descubrimos una fantasía sectaria o de club: el sueño de una solidaridad predestinada entre aquellos pocos elegidos que saben leer. Para el mundo antiguo, y hasta la antesala misma del Estado nacional moderno, saber leer significaba de hecho algo así como ser miembro de una elite envuelta en un halo de misterio (Sloterdijk, 2000, p. 24).

En términos generales, pues, el humanismo es un fenómeno literario que consiste en una serie de tradiciones filosóficas escritas que aglutinan en torno suyo el interés de generaciones sucesivas sobre las cuestiones humanas. Entre 1789 y 1945 , el humanismo adquiere un cariz político fundamental: el Estado-nación (uno de los más ambicio- sos proyectos de la Modernidad) se erige sobre el cultivo de un canon de lectura compartida por los ciudadanos, y sobre la exaltación de unos clásicos (universales, pero sobre todo nacionales) que expresan en sí mismos el espíritu de la nación. Es así como, gradualmente, empiezan a configurarse las lenguas vernáculas (francés, alemán, inglés) y junto con estas las literaturas y las filosofías nacionales:

[...] el ejemplo de la sociedad literaria se amplió hasta convertirse en norma para la sociedad política. A partir de ahí los pueblos se organizaron a modo de asociaciones alfabetizadas de amistad forzosa, unidas bajo juramento a un canon de lectura vinculante en cada espacio nacional (Sloterdijk, 2000, p. 25).

Este vástago de la Ilustración que es el Estadonación, esta ficción literaria de una comunidad de lectores que comparte unos mismos autores y unos ciertos cánones de lectura, pierde toda plausibilidad desde el momento en que los mass media entran en escena. Cuando aparecen la radio (1918) y la televisión (1945) -y más aún hoy con internet- las síntesis sociopolíticas y culturales se levantan en otros territorios distintos de aquellos en los cuales media todavía la palabra escrita ${ }^{1}$.

Desde esta primera perspectiva, Sloterdijk constata la inviabilidad de cualquier humanismo y esboza una incipiente teoría de la comunicación según la cual la irrupción de las nuevas tecnologías y los medios de comunicación ha hecho inocua la apelación a las ficciones literarias para sustentar las macroestructuras económicas y políticas. No obstante esta crisis cultural del humanismo en general, después de 1945 se volcaron en la arena nuevas apuestas humanistas que buscaban resarcir la barbarie acaecida durante la Segunda Guerra Mundial. Existencialismo y marxismo son dos de las propuestas humanistas posbélicas que pretendieron hacer carrera en la definición de un mejor futuro para la humanidad. Sin embargo, esta indignación profunda ante la degradación y la barbarie deja entrever uno de los rasgos decisi-

1. En un ensayo ya famoso, el sociólogo francés Pierre Bourdieu sostiene la tesis de que la televisión, en su afán por llegar a un mayor número de audiencia, simplifica enormemente la realidad y la convierte en un entretenimiento banal e incomprensible. Lo que no queda bien en su formato - brevedad, apoyo con imágenes, espectacularidad- queda silenciado o relegado y deja de tener relevancia pública. No obstante la banalización de la realidad, los formatos televisivos, por su ligereza y seducción, terminan haciendo la diferencia en el ámbito de la opinión pública. Por otro lado, Bourdieu contrapone abiertamente el formato televisivo a estilos de producción cultural como la literatura y la filosofía, entre otros: "Pienso, en efecto, que la televisión, a través de los diferentes mecanismos que intento describir de forma sucinta (...) pone en muy serio peligro las diferentes esferas de la producción cultural: arte, literatura, ciencia, filosofía, derecho; creo incluso, al contrario de lo que piensa y lo que dicen, sin duda con la mayor buena fe, los periodistas más conscientes de sus responsabilidades, que pone en peligro no menor la vida política y la democracia” (Bourdieu, 1996, p. 7). Para profundizar, ver: BOURDIEU, P., Sobre la televisión, Anagrama, 1996, Barcelona, 2a Ed. 
vos del humanismo, rasgo que gradualmente nos irá conduciendo a profundidades cada vez más peligrosas.

En efecto, Sloterdijk muestra que la defensa de la dignidad humana da cuenta de que el humanismo siempre tiene un "contra qué", a saber, rescatar a los hombres de la barbarie. Incluso muchos siglos antes de los episodios catastróficos de la Segunda Guerra, cuando Cicerón recorría las calles, teatros y plazas de Roma, el humanista veía su misión en el rescate de sus congéneres de aquellos dispositivos de crueldad y desinhibición que fueron los espectáculos sangrientos esparcidos a lo largo y ancho del Imperio. En este sentido, el humanismo es una forma de resistencia ante las tendencias desinhibidoras inscritas en la condición humana (la violencia, la crueldad) por medio de la apelación a dispositivos de contención como la lectura, la meditación y la filosofía: "El sentido de dicha elección de medios reside en desacostumbrarse de la posible brutalidad propia y guardar las distancias con la escalada de deshumanización de la jauría vociferante del teatro" (Sloterdijk, 2000, p.35).

A la superficial definición del humanismo como sociedad literaria-educativa, hay que agregar ahora (con una profundidad creciente) la del humanismo como antropodicea, es decir, como una posible respuesta a la pregunta acerca de cómo puede el hombre convertirse en un ser humano verdadero o real y qué medios o instrumentos de comunicación podrian usarse para que el hombre concuerde con aquello que debe ser.

En este punto, las Normas para el parque humano entra en su segunda fase. Luego de dar una definición general del humanismo, el filósofo alemán hace el recuento de su crisis en el siglo $X X$. En este punto su interlocutor principal es el Heidegger de la Carta sobre el humanismo. Este documento se inscribe en lo que se ha denominado en el universo de comentadores y discípulos del filósofo de Friburgo, el fin de la metafísica. Con este término se alude de manera muy general, a esa situación en virtud de la cual el ser ya no va más en su disposición en cuanto ente, sino que, por el contrario, es liberado y entregado a la temporalidad que lo constituye.

Esta terminología se resuelve en el texto de Heidegger en una indicación sumamente precisa: la filosofía moderna ha pensado el ser en cuanto sujeto cognoscente (este es el sentido de la afirmación según la cual en Occidente en lugar del ser siempre se ha puesto un ente). Ahora bien, esta primacía del sujeto que conoce se convertirá en la condición de posibilidad de las diversas manifestaciones del humanismo moderno. $\mathrm{Y}$ es precisamente contra este humanismo fundado en la idea de un sujeto definido por su posición de sujeto que conoce, que Heidegger dirigirá todo su arsenal conceptual.

Esta referencia breve al pensamiento de Heidegger y sobre todo a su crítica al humanismo moderno como coronación de la metafísica de la subjetividad, despeja el horizonte de reflexión de la filosofía crítica. En efecto, Nietzsche, Marx y Freud abren en el siglo XIX una brecha profunda en el corazón de la época moderna cuando atisban que el progreso, la razón y la moral no son sino efectos de superficie de procesos que escapan a la presunta omnipotencia de la consciencia del sujeto cognoscente (llámese voluntad de poder, inconsciente o lucha de clases). Lo que sí queda claro desde este momento es que la tesis según la cual es la consciencia la que determina la vida se invierte: antes bien, es la vida la que determina la consciencia. Y en el siglo XX, a pesar de las diversas modulaciones filosóficas que pueda presentar esta tesis, seguirá planteándose la pregunta acerca de lo que pasa con el sujeto que conoce cuando ha sido hendido en el centro por la embestida de estos trascendentales que lo determinan ${ }^{2}$.

Ahora bien respecto del texto de Sloterdijk, quisiera rescatar algunas tesis que pueden resultar claves para delimitar el campo de reflexión. En primer lugar, es evidente el tono burlesco con el que Sloterdijk trata la dimensión política de la reflexión heideggeriana. En algún apartado sostiene:

Heidegger enaltece al Ser como único autor de toda carta esencial, y se asigna a sí mismo el papel de secretario. Quien habla desde esa posición debe incluso registrar balbuceos y hacer públicos silencios. El Ser envía, entonces, las cartas decisivas [...] hasta

2. En su libro Las palabras y las cosas, Michel Foucault cierra sus reflexiones afirmando la contingencia de la figura del hombre y vaticinando, acertadamente, el advenimiento de una época en que los saberes ya no habrían de girar en torno de esta invención reciente que es el hombre, sino alrededor del lenguaje o el inconsciente (en el caso del psicoanálisis). 
donde podemos ver, a partir de estos círculos de copastores y amigos del Ser no se constituyen naciones, ni siquiera escuelas alternativas -y no sería la menor razón de esto la imposible existencia de un canon claro de los guiños del Ser-, con lo que ha de quedar entonces por ahora la obra completa de Heidegger como voz y piedra de toque del superautor innominado (Sloterdijk, 2000, pp. 14-15).

La salida de Heidegger al espíritu instrumentalizador y cosificador de los humanismos es, pues, el planteamiento de una nueva mística según la cual el Dasein sale del círculo de impiedades del mundo moderno occidental para morar junto al Ser en un estado de serenidad y escucha casi contemplativos. Pero Sloterdijk -tal vez más cerca de Nietzsche y de Foucault- parte del hecho de que la cultura occidental expresa una voluntad de domesticación del ser humano que resulta insoslayable. Por esta razón, afirma que estos copastores del ser heideggeriano no constituyen naciones (ni siquiera escuelas alternativas) como sí se constituyeron naciones a partir de cánones de lectura compartidos por un pueblo (este es uno de los sentidos esenciales que Sloterdijk halla en el humanismo).

Desde la perspectiva de Sloterdijk, entonces, Heidegger tiene el mérito evidente de haber desvelado las tendencias retorcidas de la metafísica moderna, peroa su vez comete el yerro inadmisible de mirar con el rabillo del ojo el sentido fundamental de lo político, a saber, el problema de la domesticación del hombre por el hombre, presente, por lo menos según el filósofo alemán, desde el diálogo El político de Platón.

La apelación a Heidegger sirve a Sloterdijk para plantearse el interrogante fundamental que orientará hasta el final su reflexión en Normas para

\section{el parque bumano.}

Y si los ontológicos juegos pastoriles de Heidegger -que ya en su día sonaron extrańos y chocantes-nos parecen hoy completamente anacrónicos, con todo $\mathrm{y}$ sin perjuicio de que resulten penosos y retorcidamente extravagantes, siguen teniendo el mérito de haber sabido articular correctamente la pregunta de la época: ¿qué amansará al ser humano si fracasa el humanismo como escuela de domesticación del hombre? ¿Qué amansará al ser humano, si hasta ahora sus esfuerzos para autodomesticarse a lo único que en realidad y sobre todo le han llevado es a la conquista del poder sobre todo lo existente? (Sloterdijk, 2000, p. 55).

Si bien Sloterdijk reivindica el espíritu posthumanista de Heidegger, también es cierto que plantea una crítica radical del pensamiento del filósofo de Friburgo. Esta crítica consiste fundamentalmente, en el hecho de que la concepción heiddegeriana del ser humano obvia su carácter biocultural. Para Sloterdijk, en cambio, el ser humano (Clairiere) es un fenómeno compuesto básicamente por dos dimensiones esenciales:

1. Una historia natural de la serenidad, la cual expone la manera como el hombre pudo convertirse en un ser abierto al mundo ${ }^{3}$.

2. Una historia social de los amansamientos que pone en evidencia la manera como los hombres se recogen (en el sentido de crear cultura, pero también de refrenarse, de contenerse) para corresponder al todo.

Uno de los pensadores modernos más significativos en lo que se refiere, entre otros, al problema de la historia social de los amansamientos es Friedrich Nietzsche. No es gratuito que Sloterdijk lo cite permanentemente para introducir la cuestión de la crianza, la selección y la domesticación del ser humano. El sentido de las alusiones a Nietzsche pasa por dos puntos esenciales: en primera instancia, para desvelar el humanismo como una escuela disimulada de crianza y selección; y en segundo lugar, para esgrimir la tesis de que el ser humano es el producto de una serie de técnicas aplicadas sobre sí mismo (esto es lo que Sloterdijk denomina antropotécnicas).

Como se anotó anteriormente, el humanismo es un esfuerzo contra la barbarie; una estrategia de contención a través de la lectura y de la educación, de los impulsos de desinhibición que habitan el corazón del hombre. De allí la candidez y la aureola de mártir del humanista: este, apelando a los autores clásicos, cree entablar una lucha titánica contra una serie de disposiciones que anteceden desde todo punto de vista a las lúcidas intervenciones

3. En su conferencia La Domestication de l'Etre, Sloterdijk dedica una capítulo a exponer los mecanismos que al entrar en connivencia hicieron posible algo así como la aparición de un ser que tiene mundo (el hombre). Estos son: 1. El mecanismo de insulación; 2. El de supresión de los cuerpos; 3. El de neotenia; 4. El de trasposición. 
de la razón humana. Nietzsche, eximio buceador de las profundidades del alma humana, encuentra por el contrario que esas tendencias retorcidas y esa barbarie no son disposiciones que antecedan a la existencia, sino producciones histórico-culturales, efectos de luchas y rapiñas inconfesables.

Pues bien, el humanismo y el cristianismo con sus ideales de virtud, de bondad y de justicia no emanan directamente de alguna esencia trascendental y pura. Es más: el bien del cristianismo es un producto del resentimiento, al igual que los ideales del humanismo burgués. Por esta razón, afirma Sloterdijk:

El recelo de Nietzsche frente a toda cultura humanística exige que se airee el secreto de la domesticación de la humanidad. El pretende llamar por su nombre a los que hasta ahora han ostentado el monopolio de la cría-los curas y los profesores- que se presentaban como los amigos del hombre. Nietzsche pretende nombrar su silenciada función y lanzar un debate de otro tipo, en términos de historia universal, entre diferentes criadores y diferentes programas de cría. (Sloterdijk, 2000, p. 64).

He aquí pues, la faz biopolítica del pensamiento nietzscheano que habría de desarrollar en el siglo XX Michel Foucault. Sloterdijk afirma que la escuela -entre otras- no ha sido otra cosa diferente a un dispositivo en el que se ha disimulado la verdadera labor de domesticación y cría de la especie que ha desempeñado el humanismo. Una acción aparentemente tan natural como la lectura se presenta a los ojos de un filósofo de la sospecha como un dispositivo de crianza: "[...] cabría, entonces, definir a los hombres de otros tiempos como aquellos animales de los cuales unos leen y saben escribir, y otros no. De aquí solo hay un paso hasta la tesis de que los hombres son animales de los cuales unos crían a sus semejantes, mientras que los otros son criados" (Sloterdijk, 2000, p. 69).

En este punto resulta claro por qué el discurso pronunciado por Sloterdijk levantó tanta polémica: la apelación a filósofos como Heidegger y Nietzsche aunada a la crítica al humanismo como proyecto de domesticación y crianza de la especie, despertó en una cierta facción de la vida intelectual alemana el fantasma vigilante de los campos de concentración. Es más: Sloterdijk muestra que la propuesta nietzscheana, como se vio con anterioridad, es más por una competencia entre proyectos de domesticación y cría (los que crían hacia abajo y los que crían hacia formas superiores de vida), y no por una naturaleza humana que sea menester realizar, tal y como ha pensado el humanismo a lo largo de los tiempos ${ }^{4}$.

Uno de las cuestiones más importantes de la agenda de nuestro tiempo es la referente a la tecnología, su aplicación a la vida humana y los potenciales efectos que tal aplicación puedan surtir sobre la existencia del hombre en particular y sobre la vida en general. Si bien es cierto que Reglas toca este punto, Sloterdijk trabaja con mayor detenimiento esta problemática en La Domestication 5 .

En efecto, allí el filósofo alemán sostiene fundamentalmente que claro (concepto heideggeriano) y devenir humano son dos expresiones que designan lo mismo. En este punto, Sloterdijk apela al concepto de entorno (umwelt) esgrimido por Von Uexküll ${ }^{6}$. Esta apelación le sirve al filósofo alemán para mostrar que la especificidad del ser humano es precisamente la salida del entorno natural y la apertura a eso que denominamos mundo. Por esta razón, la ontoantropología sloterdijkeana se interroga sur les deux à la fois: sur l'extase humaine,

4. Nietzsche y Foucault son, entre otros, dos de los pensadores más incisivos en su denuncia y crítica de las pretensiones del humanismo burgués. Sobre todo el segundo despliega las consecuencias teórico-prácticas de dos tesis esenciales: 1 . El hombre, como objeto de discurso, es un efecto de desplazamientos profundos en el terreno de la episteme moderna (S. XIX); 2. Este hombre que se vuelve objeto de discurso y de conocimiento, es, además, el producto de una cierta configuración de las relaciones de poder que se dan en la sociedad moderna-disciplinaria. Sloterdijk plantea su reflexión sobre el hombre partiendo de una tesis que coincide, desde todo punto de vista, con los desarrollos teóricos de Foucault: para entender el proceso de domesticación y crianza del ser humano hay que abandonar la idea de una crianza detrás de la cual hay un criador o un centro de decisión específico (el cristianismo, la clase...); antes bien, el proceso de configuración del ser humano debe entenderse como una corriente biocultural sin sujeto.

5. Me he visto en la necesidad de traducir algunos fragmentos del libro de Peter Sloterdijk La Domestication de l'Etre, debido a que no existe traducción al español de dicho texto.

6. El biólogo y filósofo alemán Jakob Von Uexküll (1864-1944) fue uno de los precursores de la etología junto con Konrad Lorenz. En sus estudios propiamente biológicos, Uexküll describe los procesos fisiológicos que permiten la interrelación entre el organismo y el ámbito exterior al sujeto, el cual es vivenciado desde la perspectiva del mundo interior del organismo (percpeciones, sensaciones). En este sentido y de manera general, el concepto de entorno (umwelt) se refiere al circuito significativo que se da entre los estímulos externos y el mundo interior del organismo, el cual permite su desenvolvimiento funcional en el entorno vital que le corresponde. Ver: Von Uexküll, Jakob. (1934). Ideas para una concepción biológica del mundo. Espasa-Calpe. Siglo XX. Madrid. 
qui porte le nom d'être dans le monde, et sur l'ancien animal qui a connu ce devenir extatique (Sloterdijk, 1999, p. 28).

\section{La domesticación del ser en Sloterdijk: precisiones sobre lo monstruoso y lo posmoderno}

El término nihilismo va de suyo con lo que desde hace más o menos tres décadas algunos filósofos han convenido en llamar posmodernidad. En su texto La Domestication de l'Etre, Sloterdijk dedica varias páginas a esgrimir su perspectiva sobre este acontecimiento.

De acuerdo con su lectura del discurrir del siglo precedente, el pensador alemán encuentra que las corrientes filosóficas más significativas se caracterizan por una reflexión radical sobre las grandes circunstancias que se instalaron en el corazón de los tiempos:

Si l'éttonnement du XX siècle porte surtout les coleurs de l'étrangeté et de l'effroi, c'est parce que les bouleversements de l'epoque se sont prolongés jusqu'au coeur du discours philosophique. Les détonations des batailles de la Marne et de Verdun continuent à resonner dans les réflexions de la phénomenologie de Marbourg et de Fribourg, les cris sortis des caves de torture de la Gestapo pénètrent jusqu' au coeur des concepts de 'existentialisme parisien; l'atrocité des politiques d'extermination en Allemagne, en Russie et en Asie poussent certains penseurs, après 1945, à se demander comment la pensé de l'Etre, face à l'autre, menacé de disparition, peut êrtre acheminée vers una pensée de la responsabilité (Sloterdijk, 1999, p. 11).
Si sumamos a estas situaciones catastróficas las bombas de Hiroshima y Nagasaki, puede entenderse por qué luego de la primera mitad del siglo XX aparecen en el horizonte filosófico formas nuevas de humanismo, tales como el neomarxismo y el existencialismo, entre otras, que buscan -como afirmara Sloterdijk en sus Reglas-contener el proceso inevitable de barbarie en que se convirtió el proyecto de la Modernidad. Este pensamiento de las grandes circunstancias (así denomina el pensador alemán a los movimientos filosóficos y artísticos que se derivan de las fuentes más importantes del pensamiento del siglo XIX) se caracteriza, pues, por plantear una reflexión fundamental sobre las situaciones límite a las que se ha visto avocada la existencia humana (de allí, por ejemplo, la predilección del existencialismo por situaciones como la angustia, la náusea, y en general, el extrańamiento del mundo).

Sin embargo, luego de la década del setenta el ambiente cultural en Occidente empieza a sufrir cambios de suma importancia. En efecto, si Sartre y sus contemporáneos vivieron una época en la cual la tortura estaba a la orden del día, después de los setenta al parecer entramos en una época dominada, principalmente, "por los mitos de la comunicación, del consumo, de la rentabilidad creciente y de la movilidad" (Sloterdijk: 1999, p. 14$)^{9}$.

En su obra Crítica de la modernidad, el sociólogo francés Alain Touraine sostiene que

[...] lo más visible (entre el siglo XIX y el XX, en relación con el proyecto ilustrado) es la disociación

7. "Sobre los dos a la vez: sobre el éxtasis humano, que lleva el nombre de estar-en-el mundo, y sobre el viejo animal que ha conocido este devenir extático" (p. 28). Esta cita es de suma importancia para comprender el proyecto de la ontoantropología, toda vez que la diferencia ontológica de que va a hablar Sloterdijk no es ya aquella diferencia entre el ser y el ente, sino antes bien la diferencia ontológica entre en-torno y mundo. Es decir: la diferencia entre una condición ontológica más limitada (el entorno) y una condición cada vez más abierta e indeterminada (el mundo). El animal tiene entorno, es decir, habita un espacio con el que está perfectamente sincronizado a través de sus sistemas biológicos (internos y externos); en este espacio la incertidumbre es mínima: los estímulos provenientes del exterior encuentran en el ser vivo una respuesta adecuada y paradigmática. El hombre, en cambio, tiene mundo. Este animal neoténico, debido precisamente a su situación de retardo biológico, se ve despedido del entorno y obligado a fundar un mundo. Uno de los capítulos de la novela ontoantropológica consiste, por esta razón, en dar cuenta del proceso de hominización, esto es, en mostrar cómo en algún punto del proceso de hominización aparece una especie de seres nacidos prematuramente que sacó ventaja de su inadaptación.

8. "Si la perplejidad en el siglo XX lleva, sobre todo, los colores de la extrañeza y el pavor, es porque las catástrofes de la época se prolongaron hasta el corazón del discurso filosófico. Las detonaciones de las batallas de Marne y Verdún continúan resonando en las reflexiones de la fenomenología de Marburgo y de Friburgo; los gritos salidos de los espacios de tortura de la Gestapo penetran en el corazón de los conceptos del existencialismo parisino; la atrocidad de las políticas de exterminio en Alemania, Rusia y Asia empuja a ciertos pensadores - después de 1945-a preguntarse cómo el pensar sobre el ser, frente al otro amenazado de desaparición, puede ser reconducido hacia un pensamiento de la responsabilidad" (La traducción es mía).

9. En este punto, Sloterdijk afirma: "Los resultados de estas reflexiones postradicales, postmarxistas, postapocalípticas, neoescépticas, neomorales, etc., desembocan en el presente, -sobre su cara externa-, en una situación social más impregnada que nunca por los mitos y rituales de la comunicación, del consumo, de la rentabilidad creciente y de la movilidad, un nuevo El Dorado de situaciones medias" (p. 14). 
del orden del cambio y del orden del ser que antes estaban asociados en la idea de modernidad, la cual significaba a la vez racionalidad (científico-técnica) e individualismo. Ahora se acrecienta la distancia entre los incesantes cambios de la producción y el consumo y el reconocimiento de una personalidad individual que es al mismo tiempo sexualidad e identidad cultural colectiva" (Touraine, 1992, pp. 100-101).

Esta cita de Touraine sirve para ilustrar las condiciones sociales, políticas y económicas que han venido aparejadas con el advenimiento de la posmodernidad. Al parecer, en la posmodernidad definida como esa época caracterizada por el cambio permanente, ningún proyecto político (unitario y global) está en capacidad de atajar las fuerzas que impelen a los sistemas productivos y al capital a renovar constantemente su oferta de productos y servicios. Las identidades nacionales, en este sentido, sufren grandes conmociones toda vez que los individuos se sienten más consumidores que ciudadanos ${ }^{10}$.

Pues bien, a estas transformaciones alude Sloterdijk cuando concibe lo posmoderno como el declive explícito de las filosofías fundadas sobre la menesterosidad de pensar las grandes circunstancias. Por el contrario, el ambiente cultural de la posmodernidad es una ambiente neomediocre en el cual resulta imposible reapropiar los fragmentos de la herencia del pensamiento radical en declive. Para recoger un poco lo que se ha dicho hasta el momento, es necesario afirmar lo siguiente:

- La posmodernidad coincide, en primera instancia, con la imposibilidad de alcanzar una verdad última (ya sea científica, filosófica o religiosa) sobre la realidad. En una palabra, el sentido de la realidad se fabuliza. Y esta fabulización de la díada realidad-verdad trae consigo la caída de la fe en los grandes relatos que, por lo menos hasta mediados del siglo XX, quisieron mostrarse como orientadores de la existencia humana (sobre todo la idea de una razón orientada hacia sus propios fines).

- La posmodernidad se refiere a una serie de situaciones sociales, económicas, políticas y culturales en virtud de las cuales el proyecto ilustrado (identidad entre el actor y el sistema) se fragmenta en diversas partes, cada una de las cuales tiene su propia racionalidad. Esta fragmentación del orden social implica, de suyo, la fragmentación de la consciencia individual (Touraine).

- Este horizonte dominado sobre todo por las dinámicas del consumo, lleva a una especie de relajamiento de la consciencia (lo neomediocre), para la cual ya no hay situaciones límite qué pensar en el ámbito de la existencia, lo cual implica en cierta medida un riesgo significativo para la filosofía que echa raíces en el pensamiento de los filósofos de fines del siglo XIX y comienzos del siglo XX.

Pero si bien Sloterdijk cuestiona este ambiente neomediocre y esta proclividad hacialo light, también es cierto que de alguna manera el pensador alemán reconoce lo posmoderno como una forma de determinación de la actualidad. $\mathrm{O}$, por lo menos, eso es lo que parece sostener cuando afirma:

Quand onle comprend correctement, le temps présent continue plus que jamais, mais sous des formes transformées, à reclamer une pensée des grandes circonstances, précisément parce que les paradigmes des tranchées, de la torture et des camps de concentration n'ont plus d'actualité immédiate dans notre monde industrialli$s e^{11}$ (Sloterdijk, 1999, p. 16).

Aun cuando el clima de los tiempos ha cambiado y ha devenido menos agobiante, Sloterdijk sostiene que este presente etiquetado con el término posmodernidad exige, de suyo, un pensamiento de las grandes circunstancias. Ahora bien, ¿por qué habría que apelar a un pensamiento de las grandes circunstancias en un mundo que se jacta de haber caído en la trivialidad y la indiferencia? ¿Qué acontecimiento pensar en un mundo en el que, a fuerza de cambios cada vez más acelerados el acontecimiento mismo termina diluyéndose en su propia caducidad? La respuesta de Sloterdijk abre un horizonte novedoso para reflexionar acerca del talante de estos tiempos:

10. Para profundizar, ver TOURAINE, A., Crítica de la modernidad, FCE, 1992, México.

11. "Cuando se lo comprende de manera adecuada, el tiempo presente continúa reclamando más que nunca, pero sobre formas transformadas, un pensamiento de las grandes circunstancias, precisamente porque los paradigmas de la tortura y de los campos de concentración no están a la orden del día en nuestro mundo industrializado" (la traducción es mía). 
Ily a longtemps que le monstreux se fait passer comme un simple phénomène passager, une vague à la mode dont les consultants disent qu'il faut surfer dessus dès lors que les illusions rationalistes du pilotage global ont éclaté [...] Il atteint aujourd 'bui un nouvel état d'agrégat par le biais de l'autre technique nucléaire, je veux parler de la technique biologique. Celle-là aussi produit une situation qui, dans la mesure où elle déraillerait, pourrait dégénérer en une prise d'otage des sociétes par leurs propres technologies avancées ${ }^{12}$ (Sloterdijk, 1999, p. 17).

De esta manera, el acontecimiento crucial del mundo contemporáneo el filósofo alemán lo designa con el término monstruoso. Y lo monstruoso se refiere, en primera instancia, al desarrollo permanente de la técnica nuclear, pero sobre todo al desarrollo de la técnica biológica. Es sobre este discurrir de la técnica biológica (sus condiciones, sus implicaciones y manifestaciones) que Sloterdijk reflexiona a lo largo del ensayo La Domestication de l'Etre. Ahora bien, la menesterosidad de concebir la técnica biológica como una gran circunstancia en el seno del mundo contemporáneo, estriba en el hecho de que esta se constituye como una manera particular de recreación y reconstitución del hombre y del mundo. Es comprensible que la técnica nuclear demande una reflexión radical, pues su aplicación implica el riesgo de la desaparición de la vida (o por lo menos de gran parte de las formas de vida que habitan el planeta, incluida la especie humana). Por su parte, la técnica biológica, en su faz creadora, deviene en lo que Sloterdijk denomina una antropotécnica, esto es, hace parte de "[...] un théorème philosophique et anthropologique de base selon lequell'homme lui-même est fondamentalement un produit et ne peut donc être compris que si l'on se penche, dans un esprit analytique, sur son mode de production"13 (Sloterdijk, 1999, p. 18).

Esta cita permite develar el significado más profundo de lo monstruoso. Más allá del riesgo cotidiano de una catástrofe nuclear y de las fuerzas que la ciencia y la técnica modernas han liberado, lo monstruoso es una condición ontológica que consiste principalmente en el hecho de que el ser humano se concibe a sí mismo como gestor de sí. El progreso inquietante de la ciencia y la tecnología conduce a la constatación de la capacidad creadora de mundos de un ser que no tiene, en sí mismo, nada de divino. De la trascendencia a la inmanencia, el hombre se ha convertido en el resultado (no del todo previsible) de las lógicas y los dispositivos racionales engendrados en el corazón de la ciencia. Los desarrollos del conocimiento científico-técnico superan, con mucho, la capacidad racional del ser humano de prever sus efectos. He aquí lo monstruoso. La posmodernidad (momento histórico en el que se sacan las consecuencias de la muerte de Dios) es aquella época en que lo monstruoso deviene cotidiano:

Que cette visión, ce discours, cette forme de réflexion aient attendu cette époque pour pouvoir se former, à l'issue des possibilités conquises par le XIX siècle dans les domains des sciences humaines, reflète le fait qu'une partie du genre humain actuel, sous la direction de la fraction euro-americaine, a intenté avec son entrée dans l'ere hautement technologique une procédure sur ellemême et contre elle-même, dont l'enjeu est une novelle définition de l'etre humain ${ }^{14}$ (Sloterdijk, 1999, p. 32).

\section{Pensar al hombre en una época posthumanista: algunas anotaciones sobre la noción sloterdijkeana de "hombre operable"}

Con anterioridad se mencionó que el gran mérito de Heidegger fue plantear de nuevo la pregunta crucial de nuestro tiempo, a saber, ¿qué amansará al hombre luego del fracaso del humanismo? Pues bien, Sloterdijk no expone un nuevo proyecto de amansamiento o domesticación, pero sí sugiere que el desarrollo de la biotecnología (el antiquísimo sueño eugenésico) es un tema que es necesario

12. "Hace mucho tiempo que lo monstruoso se hace pasar como un fenómeno simple y pasajero, una ola de moda sobre la cual, según los consultores, hay que practicar surf, sobre todo desde que las ilusiones racionalistas del pilotaje global estallaron. Lo monstruoso alcanza hoy un nuevo estado de agregado por el rodeo de una técnica distinta de la técnica nuclear; me refiero a la técnica biológica. Esta ha producido una situación tal que, en la medida en que se cometa un desatino, podría degenerar en una captura de las sociedades en las redes de sus propias tecnologías avanzadas" (la traducción es mía).

13. “(...) un teorema filosófico y antropológico de base según el cual el hombre mismo es, fundamentalmente, un producto que no puede ser comprendido más que si, en un espíritu analítico, uno se inclina sobre su modo de producción”. (La traducción es mía).

14. "Que esta perspectiva (la ontoantropología), este discurso, esta forma de reflexión haya debido esperar hasta la época actual para poderse formar luego de las posibilidades conquistadas por el siglo XIX en el dominio de las ciencias humanas, refleja el hecho de que una parte del género humano actual, bajo la dirección de la fracción euroamericana intentó con su entrada en la era altamente tecnológica, un procedimiento sobre sí misma y contra sí misma, cuya apuesta es una nueva definición del ser humano”. 
afrontar directamente cuando afrontemos los escenarios posibles de futuro para nuestra especie.

Si el humanismo ha fracasado en su empresa; si lo que tenemos frente a nosotros cuando mentamos la palabra hombre es un proceso anónimo biocultural que se expone biológica e históricamente, entonces no hay algo que debamos abandonar con mayor premura que la idea de una esencia humana que se repite en todos y cada uno de los representantes de la especie. El concepto que Sloterdijk esgrime para plantear su oposición a la noción clásica de hombre se encierra en el concepto de hombre operable.

Fundamentalmente, la noción hombre operable alude a una cierta condición antropobiológica. Esta condición está determinada por los siguientes mecanismos:

\section{El mecanismo de instalación}

El mecanismo de instalación o aclimatación consiste en el hecho de que "grupos (de seres vivos en general) que viven juntos producen por su campo de proximidad e interacción un clima interior que funciona para sus habitantes como un nicho" (Sloterdijk, 199, p. 179). Apelando al biólogo y zoólogo Hugh Miller, Sloterdijk muestra la situación de ciertos ejemplares dentro de una horda que producen en las periferias del grupo el efecto de "une paroi vivante sur la face interne de laquelle apparait un avantage climatique pour les individus de groupe qui séjournent habituellement au

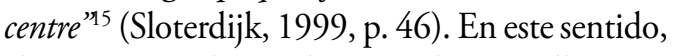
el mecanismo de instalación indica aquella situación en virtud de la cual ciertas especies animales (si no todas) tienen la capacidad de aclimatar el espacio que habitan con miras a salir airosos en la lucha por la existencia. Indudablemente hay aquí una fuerza plástica (creadora) que es el resultado a su vez de interacciones entre especies o ejemplares al interior de un grupo.

\section{El mecanismo de supresión de los cuerpos}

El mecanismo de supresión de los cuerpos tiene que ver, básicamente, con el impacto que debió tener sobre el animal pre Homo sapiens el uso de herramientas (he aquí el inicio de la carrera tecnológica). Desde una perspectiva ontológica, el uso de herramientas tecnológicas como las piedras permitió ampliar las distancias y por tanto distensionar la relación del animal pre Homo sapiens con el entorno. La supresión de los cuerpos implica "la sortie de la prison formée par la relation biologiquement déterminée avec l'environnement" ${ }^{\prime \prime 6}$. (Sloterdijk, 1999, p. 46). En este sentido, el uso de herramientas tecnológicas permite a los animales pre Homo sapiens separarse del determinsimo de la relación con el entorno y, en cierta medida, introducir una serie de acciones nuevas en el entorno que serán como el primer despuntar del mundo humano.

\section{El mecanismo de la neotenia}

Del mecanismo de la neotenia-que significa, en términos muy generales, el hecho de que en el hombre se conservan ciertos rasgos fetales que determinan precisamente su inadaptación al entorno (falta de vello corporal, ortognatismo, foramen magnum en posición central)- dependen dos situaciones de suma importancia: en primer lugar, como ya se anotó anteriormente, su inadaptación biológica; y en segundo lugar, el particular desarrollo de la masa cerebral debido precisamente a la amplitud de la cavidad craneana. En virtud de su inadaptación y labilidad biológicas (ser abierto) y con base en su capacidad cerebral y su inteligencia particulares, el Homo sapiens se instala en el mundo y climatiza su entorno a través de la cultura. Gracias a ella puede cargar a lo largo de su existencia la huella indeleble de su inadaptación (cultura es el nombre que se le da a la manera como el mecanismo de instalación, el uso de la tecnología y el mecanismo de transposición -basados todos en la condición neoténica del hombre- interactúan en la configuración de lo que se denomina mundo).

\section{El mecanismo de transposición}

Este mecanismo es de suma importancia y significa que en vista de las capacidades del Homo sapiens (fundamentalmente de su capacidad

15. "Una pared viva sobre la cara interna de la cual aparece una ventaja climática para los individuos del grupo que habitualmente permanecen en el centro". (La traducción es mía).

16. "La salida de la prisión formada por la relación, biológicamente determinada, con el entorno". 
cerebral) este ha adquirido la potencia de interiorizar lo externo, lo extrańo y al mismo tiempo de exteriorizar estados internos. De acuerdo con Sloterdijk, el lenguaje es el órgano universal de la transposición, pues a través de él no solo nos apropiamos el mundo cercano cuando lo nombramos, sino también nos permite aproximar a nuestros espacios habitables aquello que resulta inquietante y extraño. Es esta, entonces, una capacidad de simbolización de lo real (de lo que se experimenta en torno) profundamente vinculada con la capacidad de aprendizaje del Homo sapiens.

En este orden de ideas, la noción de hombre operable se refiere a aquella condición según la cual:

[...] pensar al homo humanus significa dar cuenta del nivel en que rige la ecuación de ser humano y claro. Tal como sabemos ahora, el claro, empero, no puede pensarse pasando por alto su origen tecnogénico. El hombre no se encuentra en el claro con sus manos vacías, ni como un pastor alerta, inerme junto al rebańo, como sugieren las metáforas pastorales de Heidegger (Sloterdijk, 2001, p. 08).

Con esta afirmación Sloterdijk va más allá de Heidegger. Si se parte de tales supuestos es inconcebible habitar hoy un mundo por fuera de las coordenadas digitales y virtuales que son las de nuestro mundo. Si el personaje heideggeriano por antonomasia construye su hogar en el corazón de una montaña frondosa y se dispone en silencio para escuchar los mensajes emitidos por el ser, el personaje sloterdijkeano transita las grandes avenidas virtuales de la información, dispuesto siempre a experimentar en sí mismo todo el potencial de autotransformación que la tecnología trae consigo.

No obstante, Sloterdijk no celebra irreflexivamente el potencial desatado por los poderes de la ciencia y de la técnica en el mundo contem- poráneo. En efecto, el filósofo alemán matiza su concepción del hecho tecnológico a la luz de una doble clasificación que define dos maneras diferentes de concebir y llevar a la práctica la tecnogénesis, a saber, las nociones de alotecnología y homeotecnología.

La alotecnología está profundamente vinculada con la metafísica clásica, la cual está basada a su vez en una ontología monovalente (aquella concepción según la cual el ser es y el no ser no es) y una lógica bivalente (lo que es verdadero no es falso; lo que es falso no es verdadero). Según Sloterdijk este tipo de metafísica ha configurado una noción errada, violenta y desproporcionada del acontecimiento tecnológico y de su significación para el ser humano.

En efecto, diferenciaciones dualistas tales como cuerpo-alma, sujeto-objeto, materia-espíritu y libertad-mecanismo, entre otras, han llevado a los filósofos clásicos a abordar la realidad de una manera inadecuada y a producir falsas descripciones de la misma: "Dividen a los entes en subjetivos y objetivos y colocan el alma, el yo y lo humano en un lado, y la cosa, el mecanismo y lo inhumano en el otro. La aplicación práctica de esta distinción se llama dominación"17 (Sloterdijk, 2001, p. 05).

Si desde una perspectiva teórica la alotecnología se deriva de la metafísica clásica, desde una perspectiva práctica se explicita en la relación sujeto-amo frente a objeto-esclavo; es decir, parte del supuesto según el cual el sujeto-pensante dueño de la ciencia y los dispositivos técnicos ejerce un poder absoluto sobre una materia basta y servil:

De esto surge una imagen de la técnica que sigue el modelo de las herramientas simples y las máquinas clásicas: todas ellas son medios esencialmente alotec-

17. En el panorama de la filosofía moderna, René Descartes es uno de los pensadores que expresa de manera concisa esta visión alotecnológica basada en una ontología monovalente y en una lógica bivalente. En efecto, Descartes define el mundo material (la naturaleza) por un atributo fundamental: la extensión. En este sentido, el universo es una enorme maquinaria compuesta por cuerpos extensos que interactúan de manera causal y cuantificable. La acción de medir y establecer tales proporciones y acciones y reacciones entre los cuerpos que pueblan la realidad material es uno de los principales objetivos de la ciencia (la física). Estos cuerpos (cuyos atributos centrales son la magnitud, el movimiento y la forma entre otros), su situación espacio-temporal y las relaciones de causalidad entre los mismos configuran los engranajes de la gran máquina de la naturaleza.

Por otro lado, si se añade a esta definición de la naturaleza la idea cartesiana del método como aquel camino que la mente recorre y que consiste básicamente en reducir gradualmente las proposiciones complicadas a otras más simples, para procurar luego ir de lo más simple a lo más complejo recomponiendo el orden, entonces queda claro por qué Sloterdijk sostiene que una concepción alotecnológica de la técnica y de la ciencia se expresa cabalmente en una cierta forma de dominación. Reducir el universo a formas extensas y construir un método que permita a la mente descomponer esa realidad en sus partes elementales y traducirlas a proposiciones fundamentales, implica de suyo la apropiación de la realidad por parte del sujeto que conoce en la figura de la verdad científica. Esta apropiación es la forma de dominación de la ciencia y la tecnología clásicas. Ver: DESCARTES, R. (1995). Los principios de la filosofía. Madrid, Alianza Universidad. DESCARTES, R. (1996). Reglas para la dirección del espiritu. Madrid, Alianza editorial. 
nológicos en la medida en que ejecutan reestructuraciones violentas y contranaturales de todo lo que encuentran, y en tanto que usan materia para fines que son indiferentes o ajenos a la materia misma (Sloterdijk, 2001, p. 9).

En conclusión, el concepto de alotecnología se condensa en una descripción reduccionista clásica de los entes, y en un ejercicio práctico de dominación cabal de la materia por parte de un sujeto que ha logrado apropiarse lo real a través de una supuesta apropiación de la verdad.

Lo que Sloterdijk entiende por homeotecnología supone, en cambio, un desplazamiento sustancial en relación con la tradición del pensamiento clásico sobre la técnica. El filósofo alemán procura definir su concepción de la homeotecnología a través del postulado hay información, y de sus consecuencias ontológicas y prácticas. Si la visión alotecnológica consiste en una falsa descripción dualista de los entes (entes humanos-entes no humanos, sujeto-objeto, alma-mecanismo) y en una práctica de dominación de la materia, la visión homeotecnológica implica una clara disolución de los límites dualistas de la ontología clásica y una práctica caracterizada más bien por la cooperación.

Del autómata impulsado por resortes, de la sustancia meramente extensa, puesta allí delante de un sujeto que la percibe, la conoce y la usa, se pasa a organismos vivos autopoiéticos ${ }^{18}$ capaces de organizarse y regular sus relaciones con el entorno. Es el paso de la heteronomía de la materia a la autonomía de los sistemas informados e inteligentes en la naturaleza. Y, por tanto, es al mismo tiempo la crisis del dualismo sujeto-objeto y de los fundamentos mismos de la pretensión de dominación de nuestra especie sobre la realidad. Que sea el mismo Sloterdijk quien lo formule:
La homeotecnología, al tener que vérselas con información realmente existente, no hace más que avanzar en el camino de la no-violación de los entes; gana en inteligencia inteligentemente, creando así nuevos estados de inteligencia. Toma en cuenta las cualidades de los cuerpos. Debe apoyarse en estrategias cointeligentes, coinformativas, incluso allí donde se aplica egoísta y regionalmente como ocurre en las tecnologías convencionales (Sloterdijk, 2001, p. 10).

Esta definición general de la práctica homeotecnológica (que es, de hecho, un modo auténtico de relación con la tecnología como medio de transformación de sí) echa por tierra las acusaciones de los detractores de Sloterdijk-entre los que se hallan filósofos como Habermas y Tugenhadt ${ }^{19}$. El mismo Sloterdijk no deja de burlarse de aquellos embotados malos lectores de Nietzsche (los nazis), quienes vieron en la idea del superhombre una invitación directa a experimentar la desinhibición y un retorno a lo animal. Además, es claro para aquel que se acerca concienzudamente a Normas para el parque humano que el autor es consciente del despropósito político del pensamiento de Heidegger.

En efecto, las promesas de la biotecnología en el mundo contemporáneo deben apuntar a un horizonte ético-político basado en el principio de cooperación (el ser humano está inscrito en una red de organismos y sistemas de vida inteligentes y autoproductivos con los cuales debe interactuar de manera inteligente), y no ya en el principio de dominación que ha sido el resultado de la metafísica clásica y del humanismo. En La Domestication de l'Etre, Sloterdijk no despeja a cabalidad este nuevo horizonte ético-político ni elucida el principio de cooperación que habrá de guiar una práctica homeotecnológica. Habría que esperar a las tesis contenidas en su trilogía Esferas para ver quizá desarrolladas tales tesis. No obstante, el objetivo de este ensayo era reconstruir la crítica de Sloterdijk

18 El concepto de autopoieisis se adjudica a los biólogos chilenos Humberto Maturana y Francisco Varela. Este concepto puede definirse como la capacidad que tiene un sistema (un ser vivo) para mantener un cierto equilibrio en su relación con el entorno y consigo mismo. Nótese simplemente la diferencia abismal entre esta concepción de la naturaleza y la concepción física de Descartes. Cuando Sloterdijk afirma que es menester pasar del esquema ontológico dualista a la perspectiva de la información se refiere, en cierto sentido, a este tipo de concepciones. Es muy diferente interpretar los entes partiendo del supuesto de que en su funcionamiento y modo de aparecer en el mundo hay una cierta organización y una cierta inteligencia (independientemente de que tengan consciencia o cerebro), a interpretarlos afirmando que los entes que aparecen en el mundo son solo cosas extensas sin ningún tipo de inteligencia ni finalidad en sí misma. La posición de Maturana y Varela es, desde una perspectiva ontológica, solidaria del postulado "hay información" que plantea Sloterdijk como orientador de la homeotecnología. Para profundizar en las posiciones teóricas de Maturan y Varela, ver: Maturana, Humberto R. (1997). De máquinas y seres vivos, autopoiesis de la organización de lo vivo. Santiago de Chile: Editorial Universitaria.

19. Para profundizar en el conocidísimo affaire Sloterdijk se puede consultar la siguiente página en Internet: http://multitudes.samizdat. net/-L-affaire-Sloterdijk- 
al humanismo para proyectar al mismo tiempo nuevas perspectivas para el pensamiento filosófico a la luz de lo que el filósofo alemán denomina el acontecimiento del posthumanismo.

\section{A manera de conclusión}

La deriva de esta reflexión ha atravesado, entonces, los siguientes puntos:

1. Apelando a Heidegger, Sloterdijk retoma el concepto de claro (clairiere) como forma de determinación de la condición ontológica del ser humano. Sintéticamente habría que afirmar con Heidegger que la existencia humana se caracteriza fundamentalmente por establecer una relación abierta de comprensión del ser. Ahora bien, esta relación con el ser se establece por lo menos en dos flancos: como salida del entorno natural del animal pre Homo sapiens y apertura al mundo del animal Homo sapiens; y por otro lado, como historia social de los amansamientos en virtud de los cuales unos hombres devienen criadores y domesticadores de otros (los diversos humanismos, por ejemplo, hacen parte de esta larga historia social de los amansamientos). La existencia humana o claro es pues la expresión de un proceso biocultural sin sujeto en virtud del cual el ser humano se interroga históricamente por su relación con el ser.

2. Si existe una historia social de los amansamientos de la especie humana (Nietzsche, Foucault y el mismo Marx, entre otros, caben entre los pensadores que han entrevisto tal situación), ¿¿cuál es el rasgo característico de la actualidad, del presente? Como se anotó con anterioridad, Sloterdijk plantea la tesis de que la actualidad (la posmodernidad) es aquella época caracterizada por el advenimiento de lo monstruoso (este concepto indica la capacidad autogeneradora de la especie humana a través de los dispositivos tecnológicos que ella misma ha desarrollado) como un acontecimiento cotidiano. En este sentido, la biotecnología es uno de los dispositivos más significativos en el contexto del mundo actual, sobre todo si se asocia a las posibilidades de manipulación sobre la vida que abre el descubrimiento del genoma humano.

3. El concepto de hombre operable es la síntesis de las ideas esbozadas con anterioridad. En primer lugar, ser operable significa no estar definido por una esencia humana establecida desde el origen de los tiempos sino, antes bien, estar abierto a las múltiples intervenciones de orden sociocultural que la especie ha practicado sobre su propia vida biológica. Ahora bien, esta apertura o claro no es un fenómeno que eche raíces en la actualidad. Por el contrario, lo hace en la condición antropobiológica de la especie tal cual se expuso en este ensayo. A lo largo de la historia de la especie, los seres humanos hemos pasado del uso de herramientas arcaicas a herramientas cada vez más sofisticadas: del uso de herramientas de piedra a los ordenadores de última generación. Somos animales tecnogénicos, esto es, la tecnología (arcaica o sofisticada) está en la base de lo que el ser humano es, de la manera como puede definirse a sí mismo y no es simplemente un atributo ańadido por su inteligencia o capacidad racional. La historia de la hominización camina de la mano con la historia de los dispositivos tecnológicos.

Sin embargo, hay prácticas tecnológicas inadecuadas y prácticas tecnológicas adecuadas. La concepción clásica de la tecnología se basa en el principio de dominación (alotecnología). Una nueva práctica tecnológica debe fundarse en el principio de cooperación (homeotecnología). El advenimiento de la homeotecnología implica de hecho la crisis de la metafísica y la lógica clásicas y por tanto el declive del humanismo. El ser humano -animal tecnogénico- ha llegado a un punto de progreso científico-técnológico en el cual la crisis del horizonte humanista es irreversible. Es el ingreso en una nueva era, un nuevo capítulo en la novela ontológica de la errancia de la especie. Pero no hay por qué ser pesimistas ni adoptar visos apocalípticos. El pastor del ser heideggereano ha quedado lejos de las superautopistas en la información de la era digital. La apuesta es más bien ética y política. Hay que sacar las conclusiones del principio de cooperación que plantea Slotedijk como orientador de la práctica tecnológica en el mundo contemporáneo. 


\section{Bibliografía}

- BOURDIEAU, P. (1996) Sobre la televisión, Barcelona: Anagrama.

- DESCARTES, R. (1995). Los principios de la filosofia. Madrid: Alianza Universidad.

- DESCARTES, R. (1996). Reglas para la dirección del espiritu. Madrid: Alianza editorial.

- FOUCAULT, M. (2005). Las palabras y las cosas, Buenos Aires: Editorial siglo XXI.

- _ (2005). Vigilar y Castigar, Buenos Aires: Editorial siglo XXI.

- HEIDEGGER, Martin, Carta sobre el humanismo.

- MATURANA, Humberto (1997). De máquinas y seres vivos. Autopoiesis de la organización de lo vivo. Santiago de Chile: Editorial Universitaria.

- SLOTERDIJK, Peter (1999). La Domestication de l'Etre, Mille et une nuits. Paris.

- SLOTERDIJK, Peter (2000). Normas para el parque humano, Madrid: Editorial Siruela.

- SLOTERDIJK, Peter (2001). El hombre operable. Notas sobre el estado ético de la tecnología génica. En: http:// www.revista-artefacto.com.ar/revista/nota/?p=91 (visitado el día 5 de octubre de 2012).

- TOURAINE, Alain (1994). Crítica de la modernidad, México: FCE.

- VON UEXKÜLL, Jakob (1934). Ideas para una concepción biológica del mundo. Madrid: Espasa-Calpe, Siglo XX. 